\title{
Training Psychiatrists in New Mexico: Reflections from Psychiatry Residents Who Participated in a Rural Track Versus a Traditional Program Alone over the Past Decade
}

\author{
Cynthia Killough ${ }^{1} \cdot$ Erin Rush Ortegon ${ }^{1} \cdot$ Rahul Vasireddy $^{1} \cdot$ Tyler Kincaid $^{1} \cdot$ Helene Silverblatt $^{1} \cdot$ Annette Crisanti $^{1}$. \\ Kimberly Page ${ }^{1}$
}

Received: 29 April 2021 / Accepted: 22 November 2021/Published online: 6 January 2022

(c) Academic Psychiatry 2021

\begin{abstract}
Objective With over $60 \%$ of rural Americans living in mental health professional shortage areas, there is a need for providing psychiatry residents training experiences in rural communities with the goal of increasing the likelihood that they will end up practicing in those same communities following graduation. The purpose of this study was to survey previous and current psychiatry residents, with the goal of describing the impact of the program on rural track residents compared to those in the traditional residency track.

Methods Psychiatry residents 2010-2020 completed an online survey. For those who participated in the rural residency track, the survey asked additional questions regarding barriers experienced practicing in rural areas (e.g., professional isolation) and whether the goals of the rural track were met.

Results Seventy-four residents completed surveys, with $26 \%$ in the "Rural Track Group" (RTG) and $74 \%$ in the "Non-rural Track Group" (NTG). More RTG reported they were more likely to practice in rural, frontier, or underserved areas after residency compared to NTG (74\% versus 60\%). Most RTG (72\%) strongly agreed the rural program helped meet goals. Distance from family was a top barrier for current RTG (63\%), followed by concerns about local schools, social isolation, and reduced career opportunities for partners (45\%).

Conclusions Residents of the RTG were more likely to consider a career in a rural area than those of the traditional program alone. Psychiatry residency requirements should be reviewed to address top rural training barriers to promote retention in rural areas.
\end{abstract}

Keywords Rural $\cdot$ Psychiatry $\cdot$ Residents $\cdot$ Residency program

The USA currently has a severe shortage of psychiatrists, and by 2030 it is expected that the number of psychiatrists will decrease by $20 \%$ [1]. Increased mental health awareness, access, and need related to the opioid crisis has heightened the demand for mental health providers [2, 3]. According to the Substance Abuse and Mental Health Service Administration (SAMHSA), the number of individuals in need of treatment for their mental illness grew every year for 11 years between 2008 and 2019 [4]. Additionally, the coronavirus disease 2019 (COVID-19) pandemic is creating even higher demand for mental health care [5]. Adults recovering

Cynthia Killough

ckillo@salud.unm.edu

1 Univeristy of New Mexico, Albuquerque, NM, USA from COVID-19 are twice as likely to be diagnosed with a psychiatric disorder, compared to the general population [6]. This includes increased risk of all major anxiety disorder categories, and these numbers may further overwhelm the capacity of the current mental health system [6].

The psychiatrist shortage has not spared New Mexico (NM) where mental health providers are critically needed. According to a 2019 report, "317 psychiatrists practicing in New Mexico represent a statewide psychiatrist-to-population ratio of 0.98 per 6,500 , or six below the national benchmark" [7]. NM is the fifth largest state by land area in the USA with an estimated population of 2,096,829 [8]. Approximately one-third of its people live in rural areas [9] and psychiatric care is often times more than $3 \mathrm{~h}$ away located in the larger metro areas of the state. This comes at no surprise as more than $65 \%$ of rural Americans receive mental health care from 
a primary care provider, only amplifying the need for mental health care in rural areas [10].

Evidence suggests training residents in rural areas and familiarity with smaller sized communities promotes retention in rural areas $[11,12]$. Nelson et al. [11] first recommended creating rural psychiatry training opportunities based on similar programs for Family Medicine, and Cowley et al. [12] showed success attracting and retaining psychiatrists in rural areas through rotations in those same communities.

The University of New Mexico School of Medicine's (UNM SOM) Department of Psychiatry and Behavioral Sciences offers a Rural Track to psychiatry residents. Since induction in 1991, the University of New Mexico's Rural Psychiatry Track in the Residency Program (UNM RPRP) [13] has evolved to include more psychiatry residents at an earlier stage in their residency training. This rural track provides residents experiences in facilities, such as hospitals and clinics, located in rural areas with a population less than 50,000 [14] and also serves other underserved populations throughout the state [15]. Funding from the Behavioral Health Services Division [16] allows residents to focus on their experience within rural communities through activities like touring clinics, site visits, and participating in events in the community, opposed to focusing on service demands at one site. State funding provides lodging, vehicle, and food accommodations for residents on the rural track.

Residents on this track begin discussions about possible rural rotations in postgraduate year 1 (PGY-1). During PGY2 , they spend 1 month at a rural site of their choice during which they are encouraged to live within the community and partake in local cultural events. The focus in PGY-3 is a longitudinal experience where residents spend 2 days each month at their rural site. The PGY-4 year is flexible and can accommodate longitudinal and/or shorter daily experiences. Each rotation is tailored to interests of the resident, because the ultimate goal is retention in that community.

Researchers conducted an online survey, built upon previous efforts by Bonham et al. [13], to gather information about the UNM RPRP, with the goal of describing the impact of the program on rural track residents compared to those in the traditional residency track.

\section{Methods}

Eligible participants were psychiatry residents currently in training and those that graduated within the last 10 years (2010-2020) from the University of New Mexico, Department of Psychiatry and Behavioral Sciences. From February 2020 to August 2020, researchers emailed 140 residents deemed eligible according to enrollment records, requesting them to complete the survey. Participants completed online informed consent prior to the 36-question survey through Research Electronic Data Capture (REDCap) [17]. After the initial email, up to six reminders were sent to residents, unless participants responded to the survey before the next scheduled reminder, to encourage participation.

The survey collected demographics (e.g., gender, age, ethnicity); whether participants lived in urban, suburban, or rural settings; current occupational/professional status; whether they participated in the rural program (yes/no); and, if so, their level of disagreement/agreement on the program's ability to meet their goals and objectives. Only residents that participated in the rural track completed the portion of the survey that asked for reflection on the rural/community rotation and experiences.

Descriptive statistics (measures of central tendency and variability) were generated and survey responses between rural and non-rural track groups were compared using $t$ tests for continuous variables. Differences found at $p \leq 0.05$ were considered significant. Data analyses were conducted using SPSS Version 27. The UNM Human Research Protections Office (HRPO \#20-021) approved the study.

\section{Results}

Of 140 eligible residents invited to participate, 74 completed the survey (response rate 53\%). We stratified results by those in the "Rural Track Group" (RTG; 19 of 74, 26\%), versus "Non-rural Track Group" (NTG; 55 of 74, 74\%; see Fig. 1). Of those in the RTG, 11 of 19 (58\%) were "Current Residents" who had not yet graduated from residency, and 8 of 19 (42\%) were "Former Residents" who had graduated from residency. Of those in the RTG, 14 of 19 (74\%) were male, 9 of 19 (47\%) were White, aged 35-44 years, and 11 of 19 (58\%) were current psychiatry residents. Of those in NTG, 26 of $55(47 \%)$ were female, 29 of $55(53 \%)$ were White, aged 25-34 years, and 24 of 55 (44\%) were current psychiatry residents (see Table 1 ).

Of the RTG, 11 of 19 (58\%) lived in urban areas, 7 of 19 $(37 \%)$ were in suburban areas, and none lived in rural areas. Of the NTG, 29 of 55 (53\%) lived in urban areas, 25 of 55 $(45 \%)$ in suburban areas, and 1 of $55(2 \%)$ in rural areas. Of the 8 graduates of RTG, five $(63 \%)$ were residing in NM. In RTG, 12 of 19 (63\%) lived in a rural area prior to rural program participation and 14 of $19(74 \%)$ reported they were more likely, very likely, or extremely likely to practice in rural/frontier/underserved areas in the future versus 33 of $55(60 \%)$ in NTG. A chi-square test revealed no significant differences between the groups.

Regarding barriers to practicing in rural areas, $t$ tests revealed there were no significant differences between RTG and NTG residency groups (data not shown). Current residents of RTG, 11 of 19 (58\%), reported several barriers 
Fig. 1 Total number of participants categorized by those who participated in the rural program

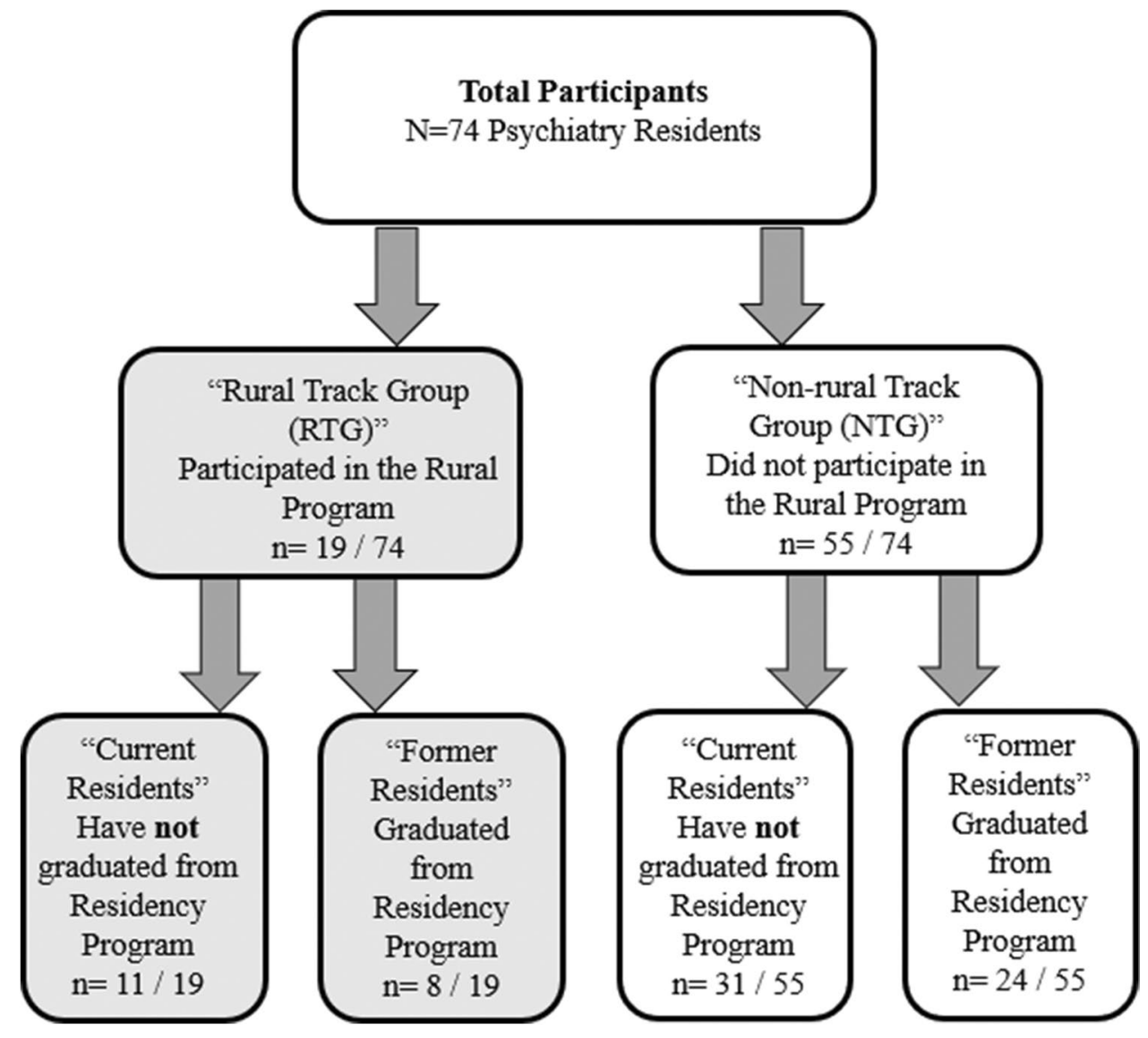

practicing in rural areas in NM: the most common being distance from family ( 7 of $11,64 \%$ ), concern with local schools (K-12), social isolation, and reduced opportunities for partners (5 of 11, 45\%). In contrast, 4 of $8(50 \%)$ of the former residents of RTG reported distance from family as a barrier, followed by 3 of 8 (38\%) "not applicable."

RTG were asked to reflect on their rural experience and rate the level of agreement/disagreement with how the rotation was able to assist them in meeting specific residency goals. Most agreed or strongly agreed the program assisted in meeting their various goals and objectives. Most notable was the strong agreement, 13 of 18 (72\%), to the following three goals and objectives: "Develop the ability to practice in a culturally different setting," "Worked on site in a rural healthcare delivery program (either primary care or psychiatric)," and "Through individual supervision, I was able to integrate my own experiences in rural practice." Residents disagreed to the following statements: 4 of 17 (24\%) "Participated in culturally relevant experiences in the community where they work," 3 of 15 (20\%) "Explored community resources such as school, churches, police, fire departments, tribal authorities and elders, and others," and 3 of 16 (19\%) "Worked with administrators of the healthcare services on issues of Medicaid, managed care, and other issues of healthcare delivery."

\section{Discussion}

This study identified important information about psychiatry resident training in NM rural communities. Most notably, current RTG perceived distance from family, concerns with local schools, social isolation, and reduced opportunities for partners when practicing in a rural area. Graduates had fewer concerns. As rural rotations are designed to expose residents to barriers specific to rural areas and help them develop skills to navigate them, missing important local experiences (such as cultural events) can have an impact on how residents perceive these barriers. Many current RTG identified they did not have the opportunity to work with other health service administrators, explore community resources, or participate in culturally relevant experiences. In 2013, the Accreditation Council for Graduate Medical Education (ACGME) launched the Psychiatry Milestone Project where residents are rigorously evaluated every 6 months. Due to the rigorous nature and frequency of the required evaluations, residency programs experienced barriers sending residents into rural communities for extended periods of time [18]. It is possible this discrepancy between past and current residents is due to new training requirements that reduced rural rotations from a year-long experience to weeks or months long. In the future, rural residency programs should be encouraged 
Table 1 Demographic characteristic information of both psychiatry residents in the Rural Track Group (RTG) and Non-rural Track Group (NTG)

\begin{tabular}{lll}
\hline & RTG & NTG \\
\hline $\begin{array}{l}\text { Participated in rural track } \\
\text { Gender }\end{array}$ & $19(26 \%)$ & $55(74 \%)$ \\
Female & $5(26 \%)$ & $26(47 \%)$ \\
Male & $14(73 \%)$ & $24(44 \%)$ \\
Do not wish to reply & 0 & $2(4 \%)$ \\
Missing & 0 & $3(5 \%)$ \\
Race (check all that apply) & & \\
Hispanic White & $7(37 \%)$ & $6(11 \%)$ \\
Hispanic Non-White & 0 & $4(7 \%)$ \\
Native American & $3(16 \%)$ & $1(2 \%)$ \\
Latino & $3(16 \%)$ & $1(2 \%)$ \\
White & $9(47 \%)$ & $29(53 \%)$ \\
African American & 0 & $1(2 \%)$ \\
Asian & $2(10 \%)$ & $7(12 \%)$ \\
Other & 0 & $4(7 \%)$ \\
Do not wish to reply & 0 & $5(9 \%)$ \\
Age & & $11(2 \%)$ \\
25-34 years & $6(31 \%)$ & $25(45 \%)$ \\
35-44 years & $12(63 \%)$ & $14(25 \%)$ \\
45-64 years & $1(5 \%)$ & $11(20 \%)$ \\
65-85+ years & 0 & $4(7 \%)$ \\
Do not wish to reply & 0 & 10 \\
\hline
\end{tabular}

to reevaluate goals of rural rotations to focus on engaging residents through informal social groups, providing continuity of care through telehealth, or adding didactic training on networking in communities and accessing local resources.

RTG felt confident in their clinical skills. When asked to reflect on their experience, most reported gaining useful clinical experience practicing in a rural area with diverse patient populations. However, approximately one-fourth of residents reported they did not receive an adequate immersion in the culture of the community in which they worked. Different educational frameworks, like structural competency, may be useful in building this inherently different kind of skill-set [19]. Perhaps most importantly, comfort with new cultures and systems of care may require lived experience and longer term placement.

The greatest barrier to rural practice identified by the RTG was distance from family, followed by concerns about local schools, social isolation, and reduced career opportunities for partners. While there is funding for logistical support for rural residents, those who wished to be accompanied by their families had to find means to cover additional costs. Residents who wish to serve rural communities must also take into consideration what life would be like for their families, including time away from family and friends if they choose to commute, and educational systems, as well as the livelihood of their partners. While many providers took care of patients from underserved and rural communities, few lived in those areas. This finding was contrary to the previous UNM RPRP study [13] in which more providers that participated in the rural program chose to live in rural areas. Changing practice patterns could be reflecting the changing landscape in the job market for psychiatrists and the growing use of telehealth, making it unnecessary for a job to be tethered to a particular geographic area.

Similarly to Family Medicine rural residency programs, the UNM RPRP offers its residence a defined rural training mission and locations in the rural state, and has a designated rural program director [11] but does not require rural rotations. During its initial development, the UNM RPRP leadership thought it best for RTG to decide where they would like to practice. The rationale being that if a resident felt called to a certain rural location, they might have more of an intrinsic desire to practice there. Results of the current study did show that residents of the RTG (74\%) were more likely to consider a career in a rural area than those of the traditional track alone $(60 \%)$.

The survey results reflect the population of residents specific to UNM and may not be generalizable to other resident programs. A limitation is one of the survey questions grouped rural, frontier, and underserved into one category and the definition for each was not defined which may have caused confusion as one participant noted NM as a whole is considered medically underserved. The data would have benefited from having those categories separated. Furthermore, the survey was not constructed in a way as to differentiate first year resident responses from other years.

Another limitation was in recruitment, leading to a small number of survey respondents. Researchers obtained contact information of some past residents from the UNM Psychiatry Department, but the UNM Alumni Office was unable to release contacts of UNM Psychiatry resident graduates. It is also important to note that data collection began in February 2020 and stay at home orders due to COVID-19 in NM began in mid-March 2020. Data collection was stalled for a few months while researchers relocated to home offices. The small number of residents also limits interpretation and generalization of the findings.

The need for psychiatrists in rural areas cannot be understated and additional research is needed to further findings found in this study. Future assessments could include a mixed-methods study to capture the variety of ways rural health has evolved since the inception of the UNM RPRP. Difficulties of cultural integration and systems-level knowledge require lived experience, which can be provided through rural residency programs in communities. Program directors and those in state leadership positions are encouraged to find ways to support psychiatry resident's time in 
rural programs to overcome these barriers while still meeting their residency requirements.

Acknowledgements The corresponding author would like to acknowledge the UNM DFCM Accountability Writing Group, Heidi Rishel Brakey, and Caroline Bonham for their assistance and contributions to our work. Kimberly Page received support from 1UL TR001449 for her contributions to this work.

\section{Declarations}

Disclosures On behalf of all authors, the corresponding author states that there is no conflict of interest.

\section{References}

1. Bureau of Health Workforce. Review Health Workforce Research. Available from: https://bhw.hrsa.gov/data-research/projectinghealth-workforce-supply-demand/behavioral-health. [Accessed 25 Oct 2021].

2. National Alliance on Mental Illness. Mental Illness Awareness Week. Available from: https://www.nami.org/get-involved/aware ness-events/mental-illness-awareness-week. [Accessed 25 Oct 2021].

3. World Health Organization. World Mental Health Day. Available from: https://www.who.int/campaigns/world-mental-health-day. [Accessed 25 Oct 2021].

4. Substance Abuse and Mental Health Services Administration. 2019 National Survey of Drug Use and Health. Available from: https://www.samhsa.gov/data/release/2019-national-survey-druguse-and-health-nsduh-releases. [Accessed 25 Oct 2021].

5. Cullen W, Gulati G, Kelly BD. Mental health in the COVID-19 pandemic. QJM An Int J Med 2020;113(5):311-2.

6. Taquet M, Luciano S, Geddes JR, Harrison PJ. Bidirectional associations between COVID-19 and psychiatric disorder: retrospective cohort studies of 62354 COVID-19 cases in the USA. Lancet Psychiatry;8:130-70.

7. Farnbach Pearson AW, Reno JR, New Mexico Health Care Workforce Committee. New Mexico Health Care Workforce Committee: 2019 Annual Report. Available from: https://www.nmhanet. org/files/NMHCWF_2019Report_FINAL.pdf. [Accessed 25 Oct 2021].

8. United States Census Bureau. U.S. Census Bureau QuickFacts: New Mexico. Available from: https://www.census.gov/quickfacts/ NM. [Accessed 25 Oct 2021].
9. Rural Health Information Hub. Rural health for New Mexico Introduction. Available from: https://www.ruralhealthinfo.org/ states/new-mexico. [Accessed 25 Oct 2021].

10. National Institute of Mental Health. Mental Health and Rural America: Challenges and Opportunities. Available from: https:// www.nimh.nih.gov/news/media/2018/mental-health-and-ruralamerica-challenges-and-opportunities.shtml. [Accessed 25 Oct 2021].

11. Nelson WA, Pomerantz A, Schwartz J. Putting "rural" into psychiatry residency training programs. Vol. 31, Acad Psychiatry. 2007;31(6):423-9.

12. Cowley DS, Keeble T, Jones J, Layton M, Murray SB, Williams $\mathrm{K}$, et al. Educating psychiatry residents to practice in smaller communities: a regional residency track model. Acad Psychiatry. 2016;40(5):846-9.

13. Bonham C, Salvador M, Altschul D, Silverblatt H. Training psychiatrists for rural practice: a 20-year follow-up. Acad Psychiatry. 2014;38(5):623-6.

14. U.S. Health Resources \& Services Administration. Defining Rural Population. Available from: https://www.hrsa.gov/rural-health/ about-us/definition/index.html. [Accessed 25 Oct 2021].

15. Rural Health Information Hub. Am I Rural? Tool. Available from: https://www.ruralhealthinfo.org/am-i-rural. [Accessed 25 Oct 2021].

16. State of New Mexico. Behavioral Health Services Division: Santa Fe. Available from: https://newmexico.networkofcare.org/aging/ services/agency.aspx ?pid $=$ NMBehavioralHealthServicesDivi sionHSD_1534_1_0. [Accessed 25 Oct 2021].

17. Harris PA, Taylor R, Thielke R, Payne J, Gonzalez N, Conde JG. Research electronic data capture (REDCap)-a metadatadriven methodology and workflow process for providing translational research informatics support. J Biomed Inform. 2009;42(2):377-81.

18. Kinzie JM, DeJong SM, Edgar L, Houston LJ, Janssen F, Macaluso M, et al. Psychiatry Milestones 2.0: Using the supplemental guide to create a shared model of the development of professional identity and expertise. Acad Psychiatry. 2021;1-6.

19. Metzl JM, Hansen H. Structural competency: theorizing a new medical engagement with stigma and inequality. Soc Sci Med. 2014;1(103):126-33.

Publisher's Note Springer Nature remains neutral with regard to jurisdictional claims in published maps and institutional affiliations. 